\title{
Disordered small intestinal motility: a rational basis for toddlers' diarrhoea
}

\author{
T R FENTON, J T HARRIES, ${ }^{*}$ AND P J MILLA \\ From the Department of Child Health, Institute of Child Health, London
}

SUMmaRY Toddler diarrhoea is the commonest cause of chronic diarrhoea without failure to thrive in childhood, but its pathogenesis remains obscure. We have studied upper small intestinal motility in three groups of children (control group 1 - children with no intestinal pathology undergoing duodenal intubation, $n=6$; control group 2 - children with gastrointestinal pathology other than toddler diarrhoea, $n=11$; control group 3 - children with toddler diarrhoea, $n=8$ ). We studied fasting motor patterns and the response of the migrating motor complex to intravenous cholecystokinin and an intraduodenal bolus of 5\% dextrose. The characteristics of the migrating motor complex in the three groups did not differ but their response to dextrose did. Intraduodenal dextrose disrupted the migrating motor complex in four out of four children in group 1; seven out of nine children in group 2; and nil of eight children with toddler diarrhoea in group 3 . We suggest that this failure of intestinal motor response may play a major role in the pathogenesis of the diarrhoea in this condition.

The syndrome described as toddler diarrhoea, ${ }^{\prime}$ chronic non-specific diarrhoea, ${ }^{2}$ or the irritable colon syndrome of childhood ${ }^{3}$ is the most common cause of chronic diarrhoea without failure to thrive in childhood, yet the pathophysiological mechanisms operating in this condition are largely unknown. Previously this syndrome was considered with other disorders to be part of the idiopathic coeliac syndrome ${ }^{4}$ and it was suggested that food intolerance caused the diarrhoea. The empirical finding, that removal of sugary fruits from, ${ }^{13}$ or increasing the fat content of the $\operatorname{diet}^{5}$ improved the diarrhoea, appeared to reinforce this view. The presence of undigested food remnants and excess starch granules, however, in the stools of patients with this syndrome ${ }^{3}$ suggests that small intestinal transit time is decreased ${ }^{36}$ and that small intestinal motility may be disordered. The recent recognition of clear cut motility patterns in the small intestine ${ }^{78}$ prompted us to examine small intestinal motility in children with toddler diarrhoea.

\section{Methods}

\section{METHODS}

Three groups of subjects were studied:

Address for correspondence: Dr T R Fenton. Dept Child Health. Institute of Child Health. 30 Guilford Street. London WCIN IEH.

Received for publication 5 January 1983

* Since the publication of this paper Professor Harries has sadly died.
Control group 1 (C1)

Three children suspected of having small intestinal pathology undergoing intubation, and three children undergoing pancreatic function tests, who were subsequently found to be normal, aged between 8 months and 11 years (five boys and one girl).

Control group 2 (C2)

Children with proven gastrointestinal disease other than toddler diarrhoea: two with ulcerative colitis, three with 'lethal protracted diarrhoea of infancy', one with mental retardation and diarrhoea, one with a VIP secreting ganglioneuroma, one with cow's milk protein intolerance, one with multiple food intolerances, one with idiopathic pancreatic insufficiency, and one with Schwachman's syndrome, aged between 4 months and 9 years (seven boys and four girls).

Patients with toddler diarrhoea (TD)

Eight patients, aged between 3.7 and 11.5 years (six boys and two girls).

After an overnight fast the patients were sedated with chlorpromazine $(2 \mathrm{mg} / \mathrm{kg}$ intramuscularly). A triple lumen catheter was positioned under fluoroscopic control so that the distal port lay in the proximal jejunum, and the proximal two ports in the duodenum. The port holes were $10 \mathrm{~cm}$ apart. The tube was perfused with $0.9 \%$ saline at a rate of 0.2 $\mathrm{ml} / \mathrm{min}$ by a pneumohydraulic constant pressure 
perfusion pump (Arndorfer Medical Specialties, Wisconsin, USA). The intraluminal pressures were measured by three transducers (Series 3, Luerlock, Gaeltec, UK), the output of which was displayed on an oscillographic chart recorder (Washington MDU-4).

Baseline recordings were made to establish the character of the fasting activity in each individual. Migrating motor complexes (MMCs) were seen as bands of high amplitude rhythmic (11-13 cpm) pressure waves which propagated from the duodenum into the jejunum. (It is possible that the sedation used might affect the MMCs. In a preliminary study, however, the fasting activity has been recorded in eight children six hours and 24-30 hours after sedation. We have been unable to recognise any consistent difference in the variables of the MMCs in each patient at these two times.) When two, or more usually three MMCs had been observed, the ability of the intravenous cholecystokinin or intraduodenal dextrose to disrupt the activity front was tested. When the latest activity front had started in the duodenum and had propagated into the jejunum (as visualised by the record from the distal port) either cholecystokinin (Pancreozymin, Boots UK Ltd) was given as a bolus dose intravenously $(0.2 \mathrm{U} / \mathrm{kg}$ body weight $)$ or $20 \mathrm{ml}$ of $5 \%$ dextrose was introduced into the duodenum as two $10 \mathrm{ml}$ boluses through the proximal port. Disruption of the MMC after such stimuli was said to have occurred if the MMC was foreshortened, and ceased within two minutes of these procedures. For the purposes of comparison all values were taken from the transducer at the distal port - that is, in the proximal jejunum, as this was the most constant reference point. The recordings were read blind by inspection both by the person performing the test and an independent observer.

Although disruption of the MMC by dextrose seemed obvious to the two observers who were reading the traces, a mathematical quantification of disruption was also devised. Figure 1 shows two MMCs recorded from a single patient. The duration of the last complex, MMC3, is shown as Td and that of the first complex MMC1, as Tn. Clearly Td is much less than $\mathrm{Tn}$ and this complex was thought on inspection to have been disrupted by the instillation of dextrose into the duodenum at the time shown (ID Dextrose). Td can be divided into TA and TB that is, the time interval before and after the disrupting stimulus. Clearly the duration of the complex after the stimulus, Tb, should be shorter in those patients in whom the complex has been disrupted, than in those in whom disruption does not occur. It is possible to derive a disruption index having calculated the expected duration of the complex after the stimulus from the value $\mathrm{Tn}-\mathrm{Ta}$.

The disruption index $=$

Observed duration of complex after stimulus

Expected duration of complex after stimulus

$$
=\frac{T b}{T n-T a}
$$

The disruption index should be much smaller in those patients in whom disruption has occurred.

This study was approved by the Standing Com-
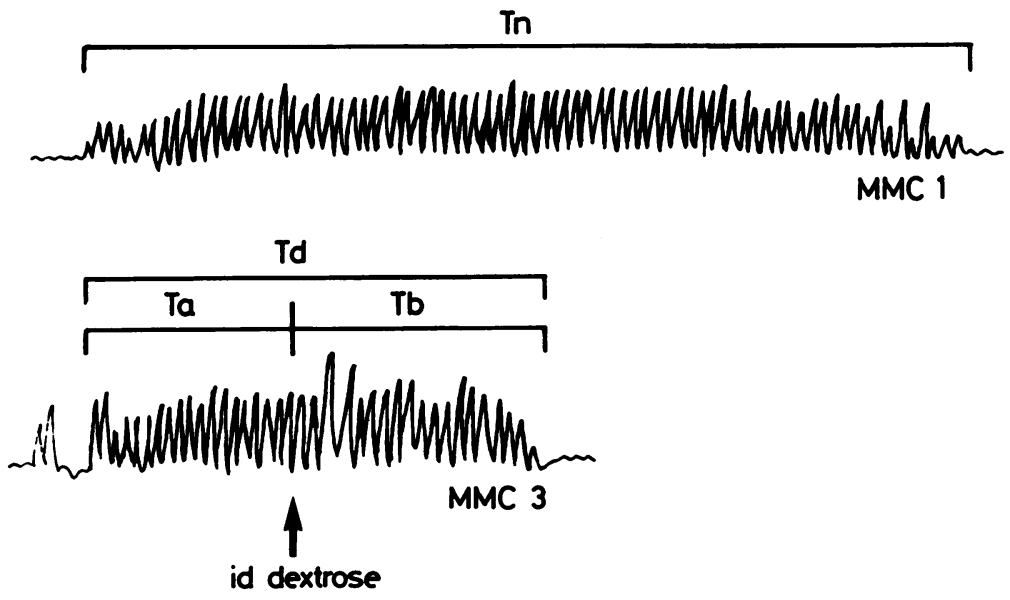

Fig. 1 Two MMCs recorded from jejunum of single patient one of which has been disrupted by intraduodenal dextrose. For explanation see text.

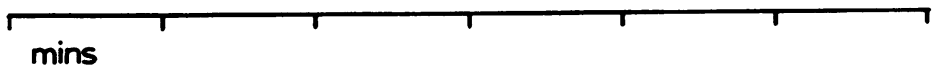


Table 1 Migrating motor complexes in children and adults

\begin{tabular}{|c|c|c|c|c|}
\hline & $\begin{array}{l}C l \\
(n=6)\end{array}$ & $\begin{array}{l}C 2 \\
(n=10)\end{array}$ & $\begin{array}{l}T D \\
(n=8)\end{array}$ & $\begin{array}{l}\text { Adults } \\
(n=18)\end{array}$ \\
\hline \multicolumn{5}{|l|}{ Duration (min) } \\
\hline Mean \pm SEM & $5 \cdot 5 \pm 0 \cdot 6$ & $7 \cdot 1 \pm 1 \cdot(0)$ & $7 \cdot 2 \pm 2 \cdot 0$ & $5 \cdot 90 \pm 0 \cdot 37$ \\
\hline Median & $5 \cdot 9$ & & $5 \cdot 1$ & \\
\hline \multicolumn{5}{|l|}{ Interval between } \\
\hline \multicolumn{5}{|l|}{$\operatorname{MMC}(\min )$} \\
\hline Mean \pm SEM & $99 \cdot 5 \pm 19 \cdot 4$ & $68 \cdot 8 \pm 12 \cdot 7$ & $68 \cdot 3 \pm 8 \cdot 9$ & $112 \cdot 5 \pm 11 \cdot 41$ \\
\hline Median & $93 \cdot 5$ & 55 & $68 \cdot 8$ & \\
\hline \multicolumn{5}{|c|}{$\begin{array}{l}\text { Propagation velocity } \\
(\mathrm{cm} / \mathrm{min})\end{array}$} \\
\hline Mean \pm SEM & $29 \cdot 5 \pm 22 \cdot 9$ & $8 \cdot 1 \pm 2 \cdot 6$ & $17 \cdot 0 \pm 2 \cdot 4$ & $11 \cdot 30 \pm 0 \cdot 14$ \\
\hline Median & 33 & 7 & $16 \cdot 6$ & \\
\hline
\end{tabular}

There was no statistical significance between the three groups of children.

The adult data are taken from a similar study in a group of unsedated adult patients. ${ }^{*}$

mittee on Ethical Practice of the Hospital for Sick Children, Great Ormond Street, and informed consent was obtained in writing, before starting the procedure, from the patients' parents.

\section{Results}

The duration of the MMC, the interval between the MMCs, and the propagation velocity of the MMCs in the three groups are shown in Table 1, together with adult values obtained at the same site by a similar technique. ${ }^{9}$ There is no difference between the three groups (Mann and Whitney $U$ test).

The effect of cholecystokinin in 'physiological' doses is clearly shown in Fig. 2, with abrupt termination of the MMC at all three sites within one minute of the injection. Cholecystokinin disrupted the MMC in four out of four control children. Figure 3 shows the disruption of an MMC in the jejunum by the introduction of dextrose into the duodenum in one $10 \mathrm{cc}$ bolus at a site $15-20 \mathrm{~cm}$ proximal to the jejunal port. The distal complex was foreshortened and terminated within two minutes of the instillation of dextrose. Children with toddler diarrhoea differed from the other two groups in their response to the dextrose which failed to disrupt the MMC as shown in Fig. 4.

The mean duration for $\mathrm{Ta}$ and $\mathrm{Tb}$ are shown in
DP

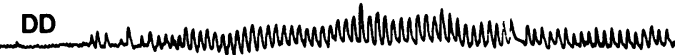

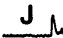
$\mathbf{T}$

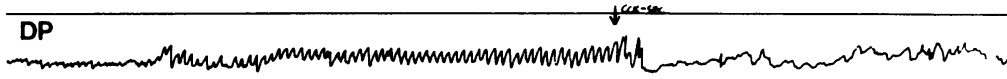

DD
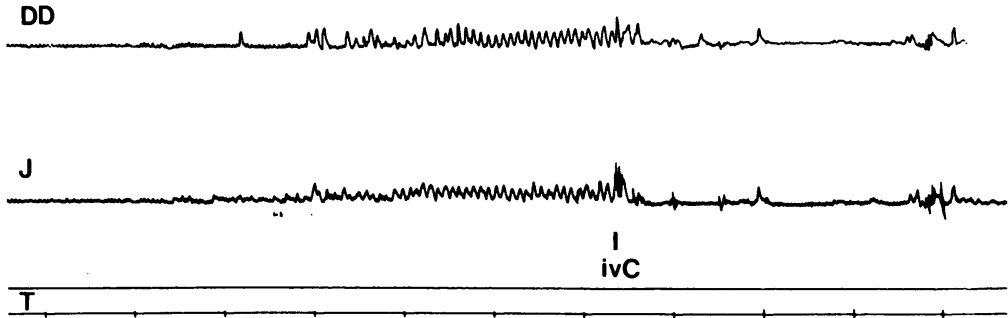

Fig. 2a Pressure record from normal patient undergoing pancreatic function test. $M M C$ can be seen. All records have the same format. $D P=$ pressure in the proximal duodenum, $D D=$ pressure in the distal duodenum, $J=$ pressure in the proximal jejunum, $T=$ time base; each deflection represents one minute.

Fig. 2b CCK $(0 \cdot 2 \mathrm{U} / \mathrm{kg})$ given intravenously (ivC) caused abrupt termination of MMC in same patient. 


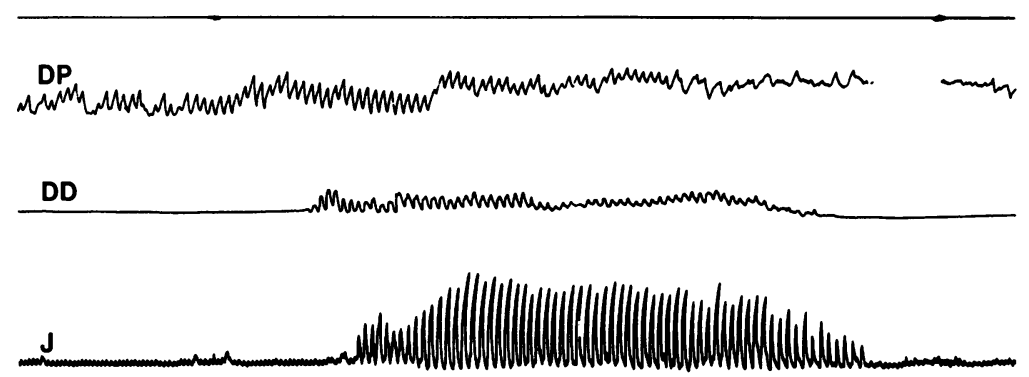

$T$
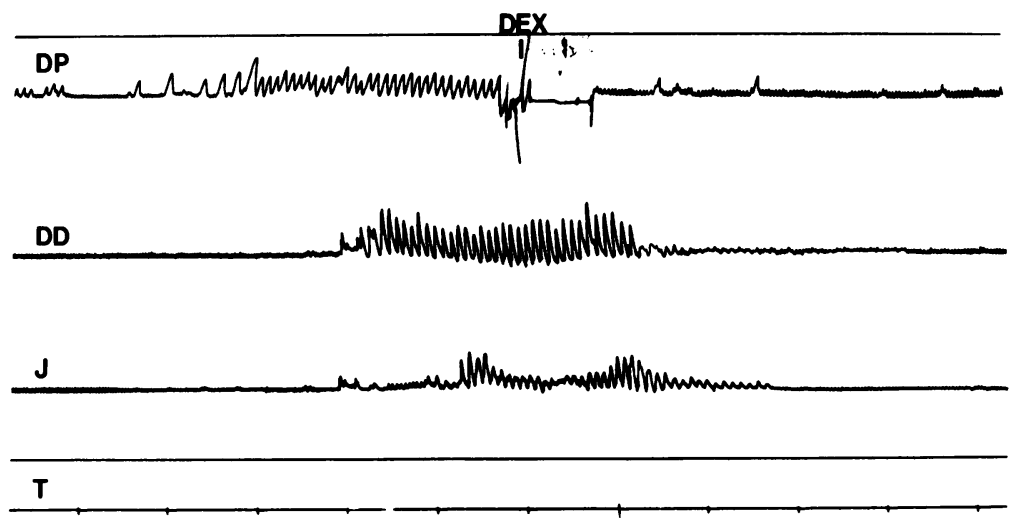

Fig. 3a MMC in normal control child.

Fig. 3b Five per cent dextrose instilled into duodenum of same child foreshortened complex in jejunum.
Table 2. There is no difference in the value of Ta for the three groups $(p>0.5)$ indicating standardisation of the timing of the stimulus. There is, however, a significant increase $(p<0.001)$ in the values of $\mathrm{Tb}$ between the children with toddler diarrhoea and the two control groups.

The values for the disruption index in each patient is shown in Fig. 5. In two patients in the control groups and two in the TD group it was possible to test for disruption on two separate occasions. The response was reproducible for each patient. All the values are shown in this Figure. The disruption index clearly separates those patients in whom the MMC appears to be disrupted by the stimulus

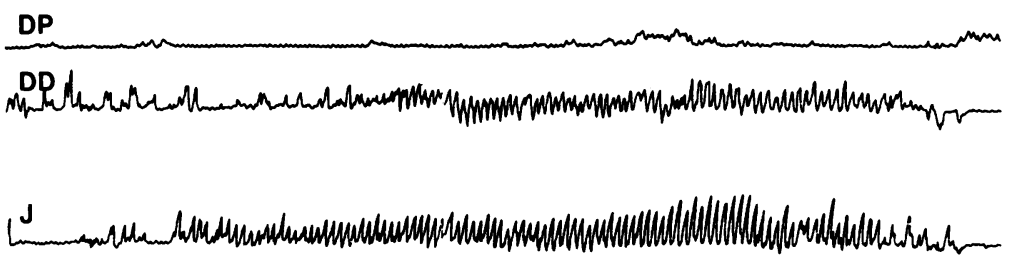

Fig. 4a MMC in child with toddler diarrhoea. 


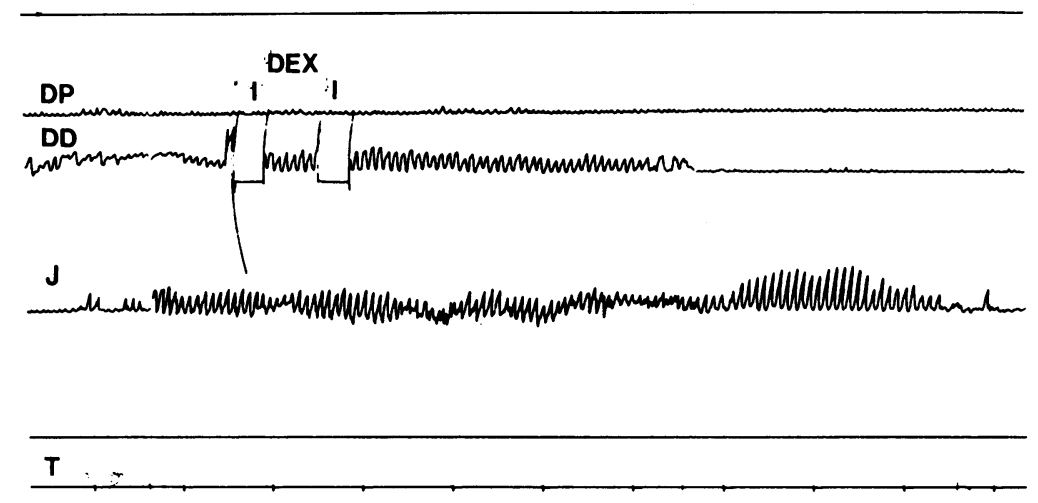

Fig. 4b Five per cent dextrose instilled into duodenum of same child failed to disrupt $M M C$.

applied from those in whom the disruption did not occur. Intraduodenal dextrose caused disruption in four out of four children in group 1, seven out of nine children in group 2, and nil out of eight children with toddler diarrhoea.

\section{Discussion}

In recent years two clear cut patterns of small intestinal motility have been described. There is a fasting pattern characterised by recurring migrating motor complexes ${ }^{78}$ which is disrupted within two minutes of eating and replaced by random

Table 2 (A) Comparison of values of Ta/Tb in MMCs disrupted by cholecystokinin and dextrose compared with those that were not disrupted by dextrose

\begin{tabular}{lllll}
\hline & & $\begin{array}{l}\text { Disrupted MMC } \\
(n=16)\end{array}$ & $\begin{array}{l}\text { Unaffected MMC } \\
(n=12)\end{array}$ \\
\hline $\mathrm{Ta}$ & $\overline{\mathrm{x}}$ & 1.74 & & 1.83 \\
& $\mathrm{SD}$ & 1.21 & $\mathrm{NS}^{*}$ & 1.46 \\
$\mathrm{~Tb}$ & $\overline{\mathrm{x}}$ & 1.55 & & 6.09 \\
& $\mathrm{SD}$ & 0.82 & $\mathrm{p}<0.001^{*}$ & 3.30 \\
& & & & \\
\hline
\end{tabular}

(B) Comparison of values of Ta/Tb in MMCs disrupted by dextrose compared with those that were not disrupted by dextrose

\begin{tabular}{lllll}
\hline & & $\begin{array}{l}\text { Disrupted MMC } \\
(n=12)\end{array}$ & $\begin{array}{l}\text { Unaffected } M M C \\
(n=12)\end{array}$ \\
\hline $\mathrm{Ta}$ & $\overline{\mathrm{x}}$ & 1.65 & & 1.68 \\
& $\mathrm{SD}$ & 1.11 & $\mathrm{NS}^{*}$ & 1.54 \\
$\mathrm{~Tb}$ & $\overline{\mathrm{x}}$ & 1.48 & & 6.09 \\
& $\mathrm{SD}$ & 0.68 & $\mathrm{p}<0.001^{*}$ & 3.30 \\
\hline
\end{tabular}

* Student's unpaired $t$ test.

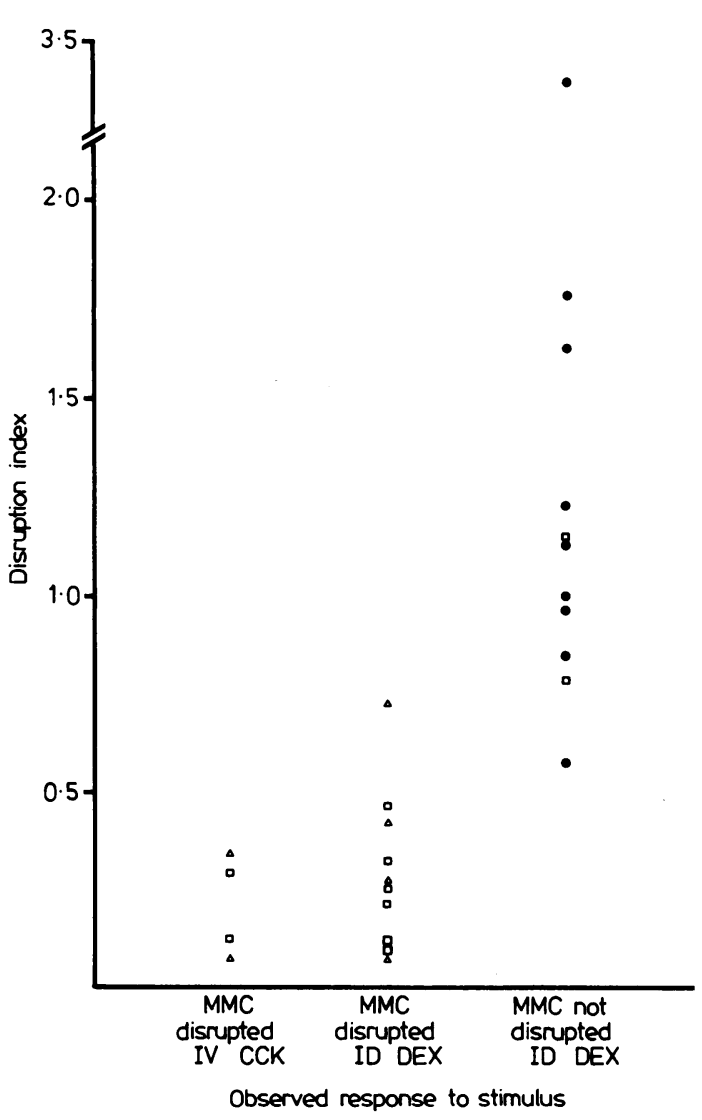

Fig. 5 Index of disruption of MMCs in children with toddler diarrhoea and controls. Patients have been grouped according to response to stimulus applied as recorded independently by two observers. Patients from $\mathrm{Cl}$ are represented by symbol $\triangle$, from $C 2$ by the symbol $\square$, and those with toddler diarrhoea by $\bullet$. 
segmenting activity, the postprandial pattern. The disruption of MMCs by various food and nutrients is well described, with fat being more efficient than other nutrients at initiating postprandial activity. ${ }^{10}$ " Although there is movement of luminal contents through the gut during the postprandial phase, this is considerably slower than that seen at times in the fasting period as measured by flow rates $^{12-14}$ and small bowel transit time. ${ }^{15-17}$ Migrating motor complexes have been shown to produce maximal flow rates through the gut in animal studies. ${ }^{18-20}$ It has been suggested that the major function of MMCs is the removal of intestinal contents following the absorption of nutrients, from the small intestine. 21

Cholecystokinin, ${ }^{22} 23$ gastrin, ${ }^{24} 25$ and insulin ${ }^{26} 27$ have all been implicated in the change from the fasting to the postprandial pattern of motility. Of these candidate hormones only cholecystokinin appears, at least in the experimental animal, ${ }^{22}$ to be associated with disruption of the MMCs in 'physiological' doses although a later report suggests that this effect may be confined to the proximal small intestine. ${ }^{28}$ Our studies show for the first time that cholecystokinin, in very small doses, has this effect in man. In addition, the direct visualisation of the effect of intraduodenal dextrose on the MMC has shown major differences between children with toddler diarrhoea and controls. The children with toddler diarrhoea fail to disrupt their MMCs in the normal way in response to dextrose. We suggest that the failure to disrupt MMCs accounts for the presence of excess starch and recognisable food remnants in the stools. The reported effects of dietary manipulation - for example, increasing the fat content of a diet - may be explained by the differing abilities of various nutrients to disrupt MMCs and induce postprandial activity. Although in this study we have not examined the disruption of the MMCs by food we speculate that the failure of disruption of the MMC by dextrose may indicate a general failure of normal disruption of the MMCs by food. This would result in a marked increase in the rate of transit of small intestinal contents which might lead to the delivery of partially digested food and excessive quantities of other substances, such as bile salts, to the colon where bacterial degradation may then yield secretagogues, such as hydroxy fatty acids and unconjugated bile salts.

Both hydroxy fatty acids and dihydroxy bile salts have been shown to induce secretion of water and electrolytes in the colon ${ }^{29} 30$ and thus may significantly effect conservation of water and electrolytes by the colon. The diarrhoea may result, therefore, from a disordered colonic function. A recent study of stool composition in children with toddler diarrhoea shows an increase in sodium, extractable water, and bile salt content. ${ }^{31}$ This study would, therefore, support our hypothesis. A similar decrease in the small bowel transit time postprandially may account for the mechanism of postvagotomy diarrhoea following the observation that the period of postprandial activity is much shorter in the postvagotomy patients with diarrhoea than those without. ${ }^{32}$

The reasons for the failure of dextrose to disrupt the MMCs in these patients are unclear. One possible cause could be a failure of a receptor in the duodenum to respond to the dextrose and trigger the normal neurohumeral effector mechanism for disrupting the motor complex in response to food. Abnormalities of small intestinal motility in functional bowel disease have been observed before,$^{33}$ but their significance has not always been clear. The defect in motility reported here, however, could play a major role in the pathogenesis of this condition.

TRF gratefully acknowledges financial support from Duphar BV, Holland.

\section{References}

1 Walker Smith JA. Toddler's diarrhoea. Arch Dis Child 1980; 55: 329-30.

2 Cohlan SQ. Chronic nonspecific diarrhoea in infants and children treated with diiodohydroxyquinoline. Paediatrics 1956; 18: 424-31.

3 Davidson $M$, Wasserman $R$. The irritable colon of childhood (chronic nonspecific diarrhoea syndrome). $J$ Pediatr 1966; 69: 1027-38.

4 Anderson DH. Celiac syndrome: VI The relationship of celiac disease, starch intolerance and steatorrhoea. $J$ Pediatr 1947; 30: 564-82.

5 Cohen SA, Hendricks KM, Eastham EJ, Mathis RK, Walker WA. Chronic nonspecific diarrhoea: a complication of dietary fat restriction. Am J Dis Child 1979; 133: 490-2.

6 Davidson $\mathrm{M}$, Bauer $\mathrm{CH}$. The value of microscopic examination of the stool for extracellular starch in the diagnosis of starch intolerance. Paediatrics 1958; 21: 565-71.

7 Szurszewski JH. A migrating electric complex of the canine small intestine. Am J Physiol 1969; 217: 1757-63.

8 Vantrappen G, Janssens J, Hellemans J, Ghoos Y. The interdigestive motor complex of normal subjects and patients with bacterial overgrowth of the small intestine. J Clin Invest 1977; 59: 1158-66.

9 Candy DCA, Larcher VF, Cameron DJS et al. Lethal familial protracted diarrhoea. Arch Dis Child 1981; 56: 15-23.

10 De Wever I, Eeckhout C, Vantrappen G, Hellemans J. Disruptive effect of test meals on interdigestive motor complex in dogs. Am J Physiol 1978; 235: E661-5. 
11 Schang JC, Dauchel J, Sava P, Angel F, Bouchet P, Lambert A, Grunier JF. Specific effects of different food components on intestinal motility. Eur Surg Res 1978; 10: 425-32.

12 Gregory RA. Some factors influencing the passage of fluid through intestinal loops in dogs. J Physiol 1950; 111: $119-37$.

13 Sarr MG, Kelly KA, Phillips SF. Canine jejunal absorption and transit time during interdigestive motor states. Am J Physiol 1980; 239: G167-72.

14 Sarr MG, Kelly KA. Patterns of movement of liquid and solids through canine jejunum. Am J Physiol 1980; 239: G497-503.

15 Bond $\mathrm{JH}$, Levitt MD. Investigation of small bowel transit time in man utilizing pulmonary $\left(\mathrm{H}_{2}\right)$ measurements. J Lab Clin Med 1975; 85: 546-55.

16 Corbett CL, Thomas S, Read NW, Hobson N, Bergman I, Holdsworth CD. Electrochemical detector for breath hydrogen determination: measurement of small bowel transit time in normal subjects and patients with the irritable bowel syndrome. Gut 1981; 22: 836-40.

17 Read NW, Miles CA, Fisher D et al. Transit of a meal through the stomach, small intestine and colon in normal subjects and its role in the pathogenesis of diarrhoea. Gastroenterology 1980; 79: 1276-82.

18 Code CF, Schlegel JF. The gastrointestinal interdigestive housekeeper: motor correlates of the interdigestive myoelectric complex of the dog. In: Daniel $\mathrm{EE}$, ed. Proceedings of the fourth international symposium on gastrointestinal motility. Vancouver: Mitchell, 1974: 631-4.

19 Bueno L, Fioramonti J, Ruckebush R. Rate of flow of digesta and electrical activity of the small intestine in dogs and sheep. J Physiol 1975; 249: 69-85.

20 Summers RW, Helms J, Christensen J. Intestinal propulsion in the dog. Its relation to food intake and the migratory myoelectric complex. Gastroenterology 1976; 70: 753-8.

21 Code CF. The interdigestive housekeeper of the gastrointestinal tract. Perspect Biol Med 1979; 2: S49-55.

22 Wingate DL, Thompson HH, Pearce EA, David A. The effects of exogenous cholecystokinin and pentagastrin on myoelectric activity in the small intestine of the conscious fasted dog. In: Duthie HL, ed. Proceedings of the sixth international symposium on gastrointestinal motility. Lancaster: MTP Press, 1978: 47-58.

23 Schang JC, Kelly KA. Inhibition of canine interdigestive proximal gastric motility by cholecystokinin octapeptide. Am J Physiol 1981; 240: G217-20.

24 Weisbrodt NW, Copeland EM, Kearly RW, Moon EP, Johnson IR. Effects of pentagastrin on the electrical activity of the small intestine of the dog. Am J Physiol 1974; 227: 425-9.

25 Marick F, Code CF. Control of the interdigestive myoelectric activity in dogs by the vagus nerves and pentagastrin. Gastroenterology 1975; 69: 387-95.

26 Bueno L, Ruckebush Y. Insulin and jejunal electrical activity in dogs and sheep. Am J Physiol 1976; 230: 1538-44.

27 Eekhout C, de Wever I, Peeters T, Hellemans J, Vantrappen G. Role of gastrin and insulin in postprandial disruption of migrating complex in dogs. Am J Physiol 1978; 235: E666-9.

28 Wingate DL, Pearce EA, Hutton $M$, Dand A, Thompson $\mathrm{HH}$, Wünsch E. Quantitative comparison of the effects of cholecystokinin, secretin and pentagastrin on gastrointestinal myoelectric activity in the conscious fasted dog. Gut 1978; 19: 593-601.

29 Ammon HV, Phillips SF. Inhibition of colonic water and electrolyte absorption by fatty acids in man. Gastroenterology 1973; 65: 744-9.

30 Mekhjian HS, Phillips SF, Hofmann AF. Colonic secretion of water and electrolytes induced by bile acid perfusion in man. J Clin Invest 1971; 50: 1569-77.

31 Jonas A, Diver Haber A. Stool output and composition in the chronic nonspecific diarrhoea syndrome. Arch Dis Child 1982; 57: 35-9.

32 Thompson DG, Ritchie HD, Wingate DL. Patterns of small intestinal motility in duodenal ulcer patients before and after vagotomy. Gut 1982; 23: 517-23.

33 Horowitz L, Farrar JT. Intraluminal small intestinal pressures in normal patients and in patients with functional gastrointestinal disorders. Gastroenterology 1962; 42: 455-64.

34 Thompson DG, Laidlow JM, Wingate DL. Abnormal small bowel motility demonstrated by radiotelemetry in a patient with irritable colon. Lancet 1979; 2: 1321-4. 